\title{
Effect of antibiotic treatment on fat absorption in mice with cystic fibrosis
}

\author{
Marjan Wouthuyzen-Bakker ${ }^{1,2}$, Marcel J.C. Bijvelds ${ }^{3}$, Hugo R. de Jonge ${ }^{3}$, Robert C. De Lisle ${ }^{4}$, Johannes G.M. Burgerhof ${ }^{5}$ \\ and Henkjan J. Verkade ${ }^{1,2}$
}

INTRODUCTION: Improving fat absorption remains a challenge in cystic fibrosis (CF). Antibiotics (AB) treatment has been shown to improve body weight in CF mice. The mechanism may include improvement in fat absorption. We aimed to determine the effect of $A B$ on fat absorption in two CF mouse models.

RESULTS: $A B$ did not improve total fat absorption. Interestingly, $A B$ accelerated the absorption of isotope-labeled fats, in both $\Delta / \Delta$ and WT mice. The changes observed were not related to the solubilization capacity of bile or to changes in the bacteria in the small intestine. $A B$ reduced the fecal excretion of cholate by $\sim 50 \%$ ( $P<0.05$ ) in both CF mouse models, indicating improved intestinal bile salt absorption.

DISCUSSION: In conclusion, $A B$ treatment does not improve total fat absorption in CF mice but does decrease fecal loss of bile salts and accelerate long-chain fatty acid (LCFA) absorption.

METHODS: For 3 weeks, we administered oral AB (ciprofloxacin/metronidazole) or control treatment to homozygous $\triangle F 508$ $(\triangle / \Delta)$, cystic fibrosis transmembrane conductance regulator (CFTR) knockout (-/-), and wild-type (WT) mice and quantified fat absorption using a 72-h fat balance test. In $\Delta / \Delta$ mice, we assessed fat absorption kinetics by administering $\operatorname{tri-1}-{ }^{13} \mathrm{C}-$ palmitin and $1{ }^{13} \mathrm{C}$-stearate intragastrically and determining the appearance of stable isotope-labeled fats in plasma. We quantified biliary and fecal bile salts (gas chromatography) and small intestinal bacteria (quantitative-PCR).

$\mathbf{T}$ he classic phenotype of cystic fibrosis (CF) in the digestive system includes malabsorption of fats. Fat malabsorption can result in a suboptimal nutritional status, thereby contributing to recurrent pulmonary infections in patients with CF (1). Therefore, the improvement of fat absorption is an important key feature in CF care. Pancreatic insufficiency is the main cause of fat malabsorption in the majority of patients with CF. Although fat absorption is greatly improved by pancreatic enzyme replacement therapy, it still remains $10-30 \%$ lower than normal in a substantial fraction of patients (2). Other causes of fat malabsorption may be a decrease in intestinal $\mathrm{pH}$, intestinal mucosal abnormalities (such as small intestinal bacterial overgrowth (SIBO), viscous mucus, and intestinal inflammation), or changes in biliary bile salt composition and/or the enterohepatic circulation of bile salts (2).

Treatment strategies other than pancreatic enzyme substitution should be developed so as to further improve fat absorption in patients with CF. Two previous studies indicated a positive effect of antibiotics (AB) treatment on nutritional status in CF conditions. Patients with CF showed improvements in body weight and BMI after 6 months of treatment with azithromycin, irrespective of changes in pulmonary function $(3,4)$. It is unclear which of the properties of azithromycin-antimicrobial or anti-inflammatory-brought about this result. CF transmembrane conductance regulator (CFTR)-knockout mice showed increases in body weight after a 3-week treatment with broadspectrum $\mathrm{AB}$, as compared with controls (5). This may reflect effective treatment of SIBO, which is a common feature in CF conditions (2) and is known to respond well to $\mathrm{AB}$ treatment in CFTR-knockout mice (5). Because intestinal bacteria are able to deconjugate bile salts, they could impair the solubilization capacity of bile (6), thereby contributing to fat malabsorption in patients with CF.

CF mice are generally pancreas-sufficient, and yet they have problems with fat absorption (7). In this regard, CF mice mimic the condition in human patients with CF who are receiving treatment with pancreatic enzymes (thereby being rendered pancreas-sufficient). The CF mouse model is therefore an excellent one in which to study fat malabsorption caused exclusively by the intestinal CF phenotype. CFTR-knockout mice have a severe intestinal phenotype, and have lower fat absorption percentages in comparison with wild-type (WT) animals. CFTR homozygous $\triangle \mathrm{F} 508$ mice, the model for the most common mutation found in CF patients, display a milder intestinal phenotype. These latter CF mice have a delayed intestinal absorption of fatty acids, as we previously demonstrated by absorption kinetics with isotope-labeled fats (7).

We aimed to determine the effect of broad-spectrum $A B$ treatment on fat absorption in both CFTR-knockout mice and homozygous $\Delta$ F508 mice. We also analyzed small-intestinal

\footnotetext{
'Department of Pediatrics, Beatrix Children's Hospital-University Medical Center Groningen, Groningen, The Netherlands; ${ }^{2}$ Department of Pediatric Gastroenterology, Beatrix Children's Hospital-University Medical Center Groningen, Groningen, The Netherlands; ${ }^{3}$ Laboratory of Gastroenterology and Hepatology, Erasmus Medical Center, Rotterdam, The Netherlands; ${ }^{4}$ Department of Anatomy and Cell Biology, University of Kansas School of Medicine, Kansas City, Missouri; ${ }^{5}$ Department of Epidemiology, Unit Medical Statistics, University Medical Center Groningen, Groningen, The Netherlands.Correspondence: Henkjan J.Verkade (h.j.verkade@bkk.umcg.nl)
} 
bacterial flora and bile salt composition, because these are potentially influenced by $\mathrm{AB}$ treatment and could provide mechanistic information on possible changes in fat absorption.

\section{RESULTS}

AB Treatment Improved Body Weight in CFTR-Knockout Mice But Not in Homozygous $\Delta$ F508 Mice

Table 1 shows the nutritional data of homozygous $\Delta$ F508 mice $(\Delta / \Delta)$, CFTR-knockout mice $(-/-)$, and their WT littermates $(+/+)$ after $\mathrm{AB}$ or control treatment. $\mathrm{AB}$ treatment did not improve body weight in $\Delta / \Delta$ mice. As seen in a previous study (5), body weight increased in the male $-/-$ mice as compared with untreated controls $(+24 \%, P=0.02)$. In our study, there were not enough female $-/-$ mice for this analysis. The multiple-regression analysis showed that $\mathrm{AB}$ had a beneficial effect on body weight in the male mice of both genetic backgrounds irrespective of the CF phenotype (C57BL/6 mice: $r^{2}=0.7, P=0.02, \mathrm{FVB} / 129$ mice: $r^{2}=$ $0.9, P=0.01)$. Parameters for fat absorption were not dependent on gender (Tables 2 and 3 ).

\section{AB Treatment Did Not Improve Fat Absorption}

In accordance with the results from previous studies (7), the total absorption of dietary fat was quantitatively similar in $\Delta / \Delta$ mice and $+/+$ mice and was not enhanced by $\mathrm{AB}$ treatment (Table 1). Total fat absorption was $\sim 4 \%$ lower in the $-/$ - mice than in the $+/+$ mice, and this did not improve after $A B$ (Figure 1a). Detailed analysis showed no changes in the absorption of saturated fatty acids in either the $\Delta / \Delta$ mice or the $-/-$ mice (Figure 1 b-c). In both CF mouse models, AB did not improve the absorption of unsaturated fatty acids (controltreated $\Delta / \Delta$ mice: $92 \% \pm 1 \%$ vs. AB-treated $\Delta / \Delta$ mice: $93 \% \pm 1 \%$,
$P=0.4$ and control-treated $-/-$ mice: $99 \% \pm 1 \%$ vs. AB-treated $-/-$ mice: $98 \% \pm 1 \%, P=0.6)$.

\section{AB Treatment Accelerated the Absorption of Fatty Acids in} Homozygous $\Delta \mathrm{F} 508$ and WT Mice

Given that $\Delta / \Delta$ mice have delayed fatty acid uptake (7), we also assessed the effect of $\mathrm{AB}$ on the kinetics of fat absorption (Figure 2). After $\mathrm{AB}$ treatment, a trend toward higher uptake was observed in $\Delta / \Delta$ mice as compared with $+/+$ mice. Of interest, the total plasma appearance (area under the curve) of $1-{ }^{13} \mathrm{C}$-palmitic acid and $1-{ }^{13} \mathrm{C}$-stearic acid was higher in AB-treated $\Delta / \Delta$ and $+/+$ mice $(P=0.04)$ than in control mice, compatible with an $\mathrm{AB}$ effect independent of $\mathrm{CF}$ phenotype (Tables 4 and 5 , respectively). The ratio of $1{ }^{13} \mathrm{C}$-palmitic acid to $1-{ }^{13} \mathrm{C}$-stearic acid was similar among the groups for all time points, indicating that the accelerated absorption was attributable to long-chain fatty acids (LCFAs) uptake and not to accelerated lipolysis. Total plasma triglycerides were similar among the groups (data not shown).

\section{Homozygous $\Delta$ F508 Mice Do Not Exhibit SIBO}

As previously reported, the $-/-$ mice displayed SIBO, and these bacteria were markedly reduced after $\mathrm{AB}$ (5) (data not shown). We analyzed the data to determine whether the $\Delta / \Delta$ mice also had SIBO. We found that the total bacterial load was similar in the small intestines of the $\Delta / \Delta$ and $+/+$ mice, and did not change after $\mathrm{AB}$ treatment (Figure 3). Given that certain bacterial species can modulate bile acid metabolism and influence fat absorption (8), and allowing for the possibility that the bacterial composition might change after 3 weeks of oral $\mathrm{AB}$, we additionally analyzed different subgroups of bacteria (Table 6). We did not find

Table 1 Mice characteristics

\begin{tabular}{|c|c|c|c|c|c|c|c|c|c|c|c|}
\hline \multirow[b]{2}{*}{ Genotype } & \multirow[b]{2}{*}{$\begin{array}{c}\text { Number } \\
(n)\end{array}$} & \multirow[b]{2}{*}{ Diet } & \multirow[b]{2}{*}{$\begin{array}{l}\text { Antibiotics } \\
\text { (mg/kg/day) }\end{array}$} & \multicolumn{2}{|c|}{ Body weight (g) } & \multirow{2}{*}{$\begin{array}{l}\text { Energy } \\
\text { intake } \\
\text { (kcal/day) }\end{array}$} & \multirow{2}{*}{$\begin{array}{c}\text { Fat intake } \\
\text { (LCT, } \\
\mu \text { mol/ } \\
\text { day) }\end{array}$} & \multirow{2}{*}{$\begin{array}{l}\text { Fecal } \\
\text { excretion } \\
\text { (g/day) }\end{array}$} & \multirow{2}{*}{$\begin{array}{c}\text { Fecal fat } \\
\text { excretion } \\
\text { (LCT, } \\
\text { mol/ } \\
\text { day) }\end{array}$} & \multirow{2}{*}{$\begin{array}{c}\text { Net fat } \\
\text { uptake } \\
(\mathrm{LCT}, \\
\mu \mathrm{mol} / \\
\text { day) }\end{array}$} & \multirow{2}{*}{$\begin{array}{c}\text { Fat } \\
\text { absorption } \\
(\%)\end{array}$} \\
\hline & & & & Pretreatment & $\begin{array}{l}\text { Post- } \\
\text { treatment }\end{array}$ & & & & & & \\
\hline \multirow[t]{2}{*}{$\Delta / \Delta$} & 4 & Chow & M: $103 \pm 20$ & $22.8 \pm 1.6$ & $22.0 \pm 0.6$ & $16.8 \pm 1.1$ & $559 \pm 38$ & $0.88 \pm 0.15$ & $40.0 \pm 5.5$ & $519 \pm 37$ & $92.1 \pm 1.2$ \\
\hline & & & $C: 51 \pm 10$ & & & & & & & & \\
\hline \multirow{2}{*}{$+/+$} & & & $C: 46 \pm 5$ & & & & & & & & \\
\hline & 4 & Chow & Control & $25.2 \pm 3.9$ & $27.0 \pm 5.0$ & $19.5 \pm 4.2$ & $653 \pm 140$ & $0.96 \pm 0.04$ & $55.0 \pm 2.3$ & $598 \pm 141$ & $90.2 \pm 2.8$ \\
\hline \multirow[t]{2}{*}{$-1-$} & 12 & Liquid & M: $93 \pm 13$ & $5.2 \pm 1.1$ & $19.2 \pm 2.1^{*}$ & $14.0 \pm 2.0$ & $313 \pm 44$ & $0.14 \pm 0.06$ & $10.6 \pm 7.0$ & $302 \pm 43$ & $96.7 \pm 2.0$ \\
\hline & & & $C: 47 \pm 7$ & & & & & & & & \\
\hline$+/+$ & 5 & Liquid & Control & $7.2 \pm 0.2$ & $20.3 \pm 2.0$ & $15.4 \pm 3.2$ & $345 \pm 72$ & $0.11 \pm 0.02$ & $3.1 \pm 0.7$ & $342 \pm 72$ & $99.0 \pm 0.3$ \\
\hline
\end{tabular}

Nutritional data of homozygous $\Delta$ F508 mice $(\Delta / \Delta)$ (FVB/129 genetic background), CFTR-knockout mice (-/-) (C57BI/6/129 genetic background), and wild-type littermates (+/+) after $A B$ or control treatment. Except for body weight in the AB-treated -/- mice, no differences were observed between the AB and control-treated mice of the same genetic background (Mann-Whitney test). The ingested amount of AB was similar between all groups (Kruskal-Wallis test). Values are depicted as mean \pm SD. $A B$, antibiotic; $C$, ciprofloxacine; CFTR, cystic fibrosis transmembrane conductance regulator; $L C T$, long-chain triglycerides; $M$, metronidazole. ${ }^{*} P<0.05$. 


\section{Articles | Wouthuyzen-Bakker et al.}

Table 2 Multiple regression analysis in CFTR-knockout mice and WT littermates

\begin{tabular}{|c|c|c|c|c|}
\hline Dependent variables & Independent variables & B & $P$ value & $R^{2}$ total model \\
\hline \multirow[t]{2}{*}{ Fat malabsorption (total) } & Genotype (WT = 0) & 2.5 & $<0.001^{\mathrm{a}}$ & \\
\hline & Treatment (control =0) & -0.38 & 0.47 & 0.53 \\
\hline \multirow[t]{2}{*}{ Fat malabsorption (saturated) } & Genotype $(\mathrm{WT}=0)$ & 7 & $<0.001^{\mathrm{a}}$ & \\
\hline & Treatment (control =0) & -1.8 & 0.16 & 0.6 \\
\hline \multirow[t]{3}{*}{ Fat malabsorption (unsaturated) } & Genotype $(W T=0)$ & 0.77 & 0.001 & \\
\hline & Treatment (control = 0 ) & 0.17 & 0.47 & 0.33 \\
\hline & Gender (female $=0$ ) & 0.19 & 0.42 & \\
\hline \multirow[t]{2}{*}{ Fecal bile salt excretion (total) } & Genotype $(\mathrm{WT}=0)$ & 10.8 & $<0.001^{\mathrm{a}}$ & \\
\hline & Treatment (control =0) & -12.1 & $<0.001^{\mathrm{a}}$ & 0.54 \\
\hline Fecal bile salt excretion (primary) & Gender (female $=0$ ) & -0.6 & 0.7 & \\
\hline \multirow[t]{3}{*}{ Fecal bile salt excretion (secondary) } & Genotype (WT = 0) & 1.4 & 0.4 & \\
\hline & Treatment (control =0) & -6.2 & $0.003^{\mathrm{a}}$ & 0.38 \\
\hline & Gender (female $=0$ ) & -4.9 & $0.014^{\mathrm{a}}$ & \\
\hline \multirow[t]{4}{*}{ Body weight } & Genotype $(\mathrm{WT}=0)$ & -3.8 & $<0.001^{\mathrm{a}}$ & \\
\hline & Treatment (control = 0) & -0.9 & 0.44 & 0.71 \\
\hline & Gender (female $=0$ ) & 0.8 & 0.51 & \\
\hline & Gender $\times$ treatment & 3.6 & $0.02^{\mathrm{a}}$ & \\
\hline
\end{tabular}

$B$, unstandardized $\beta$ coefficient; CFTR, cystic fibrosis transmembrane conductance regulator; $R^{2}$, regression correlation coefficient; WT, wild-type.

aStatistically significant.

a change in bacterial composition in either the $\Delta / \Delta$ or the $+/+$ mice after $\mathrm{AB}$ treatment. As previously reported in the case of $\mathrm{AB}$-treated mice (9), $\mathrm{AB}$ significantly increased the weight of the cecum in both $\Delta / \Delta$ and $+/+$ mice relative to controls (controls: $296 \pm 99 \mathrm{mg}, \mathrm{AB}: 489 \pm 190 \mathrm{mg}, P=0.03)$ and also the length of the cecum (controls: $2.8 \pm 0.3 \mathrm{~cm}, \mathrm{AB}: 3.6 \pm 0.7 \mathrm{~cm}, P=0.02$ ) (Figure 4).

AB Treatment Tended to Normalize Bile Salt Composition in Gallbladders of Homozygous $\Delta$ F508 Mice

We analyzed the bile salts in gallbladder bile of the $\Delta / \Delta$ and $+/+$ mice to determine whether the accelerated absorption of fatty acids after $A B$ treatment could be attributable to an improvement in the solubilization capacity of bile. In accord with the results of previous studies (10), the contribution of the primary bile salt cholic acid (CA) in gallbladder bile was found to be higher in the $\Delta / \Delta$ mice $(\Delta / \Delta: 68 \% \pm 3 \%,+/+: 44 \% \pm 1 \%, P=$ 0.04 ) (Figure 5). AB reduced the percentage contribution of $\mathrm{CA}$ and increased the percentage contribution of $\beta$-muricholic acid, resulting in a more hydrophilic bile salt composition in the $\mathrm{AB}$-treated $\Delta / \Delta$ mice (Heuman index: $-0.28 \pm 0.1$ for AB-treated vs. $-0.59 \pm 0.09$ for control-treated $\Delta / \Delta$ mice, $P=$ $0.03)$. Because hydrophobic bile salts are better able to solubilize lipids than hydrophilic bile salts are, the accelerated fatty acid uptake cannot be explained on the basis of changes in bile salt composition.

AB Treatment Reduced Fecal CA Excretion in Homozygous $\Delta$ F508 and CFTR-Knockout Mice

$\mathrm{CF}$ mice as well as human patients with $\mathrm{CF}$ have increased excretion of fecal bile salts $(2,11)$. AB treatment did not significantly change the fecal excretion of total bile salts in $\Delta / \Delta$ or $-/-$ mice ( $-40 \%$ in both CF mouse models, $P=0.06$ ). However, in comparison with controls, $\mathrm{AB}$ reduced the excretion of $\mathrm{CA}$ by $\sim 50 \%$ in $\Delta / \Delta$ and $-/-$ mice $(P=0.04$, Figure 6). In all $A B$-treated mice, the fecal excretion of the "classic" secondary bile salts deoxycholic acid and $\omega$-muricholic acid was reduced, whereas the fecal excretion of hyodeoxycholic acid was increased.

AB Treatment Reduced mRNA Expression of Muc2 in the Small Intestines of Homozygous $\Delta \mathrm{F} 508$ Mice

A reduction in mRNA expression of mucin 2 was observed after $\mathrm{AB}$ treatment in $\Delta / \Delta$ mice (AB-treated: $0.51 \pm 0.06$ vs. $0.96 \pm 0.30$ control-treated, $P=0.02$ ).

\section{DISCUSSION}

It has been previously shown that $\mathrm{AB}$ treatment eradicates SIBO and increases body weight in CFTR-knockout mice (5). 


\section{Antibiotics and fat absorption in $C F$}

Table 3 Multiple regression analysis in homozygous $\Delta \mathrm{F} 508$ mice and WT littermates

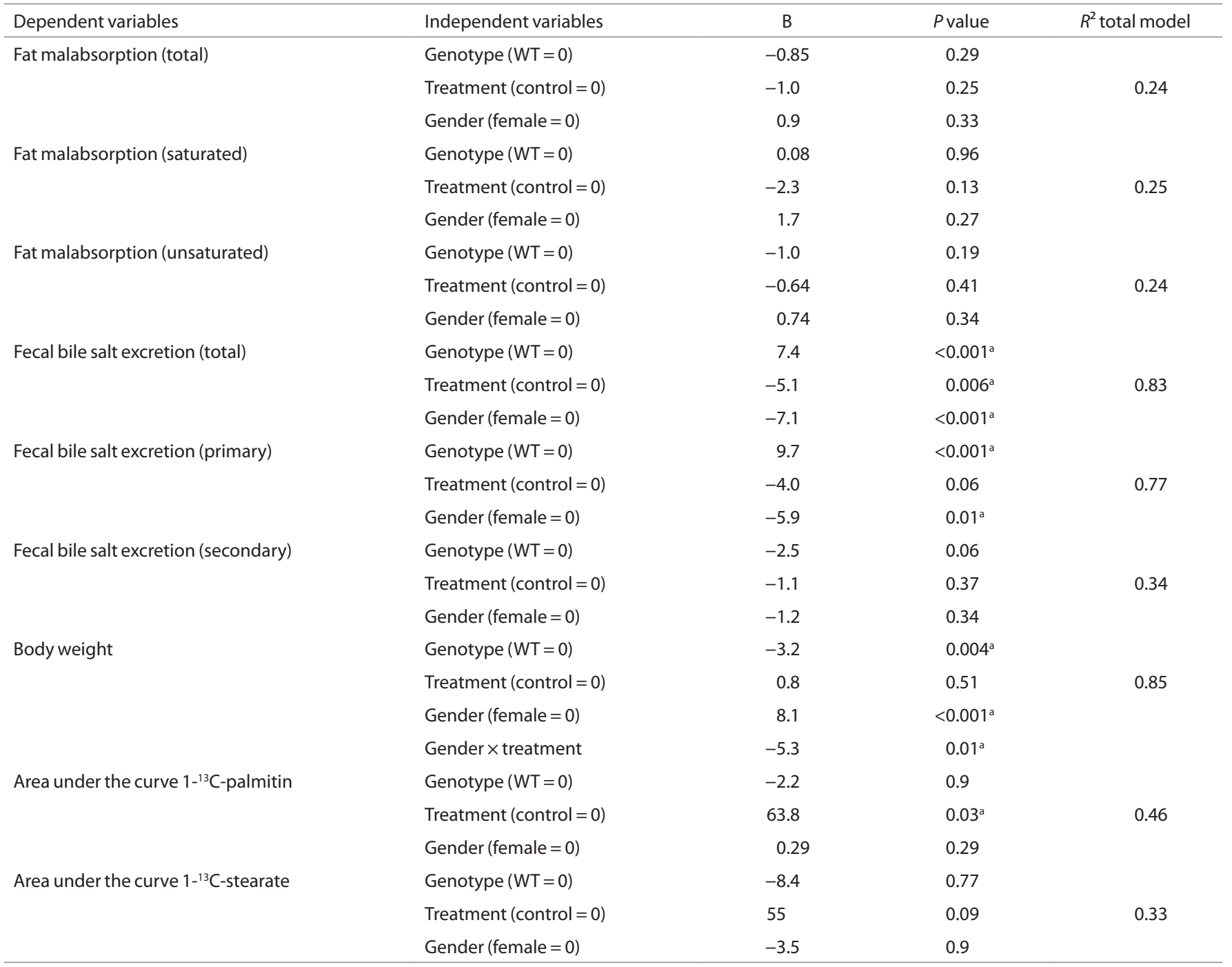

$B$, unstandardized $\beta$ coefficient; $R^{2}$, regression correlation coefficient; WT, wild-type.

aStatistically significant.

Our study adds the important finding that the positive effect of $\mathrm{AB}$ on body weight is not mediated by increasing the absorption of long-chain triglycerides. $\mathrm{AB}$ treatment of homozygous $\Delta$ F508 mice without SIBO neither augmented body weight nor increased fat absorption. Collectively, the data indicate that the positive effect of $\mathrm{AB}$ on body weight in CFTR-knockout mice may be attributable to the treatment of SIBO and not to enhanced absorption of long-chain triglycerides.

The improved nutritional status that was observed in the CFTR-knockout mice could possibly be explained in terms of other AB-related effects. It has previously been reported that $\mathrm{AB}$ effects on the small intestine in CFTR-knockout mice (reduction in bacterial load, inflammation, and mucus) can decrease energy demand and thereby improve nutritional status (12-14). Given that these intestinal mucosal abnormalities may also (theoretically) impair the uptake of proteins and carbohydrates, we cannot exclude the possibility that the absorption of these macronutrients also improved after $\mathrm{AB}$ treatment. However, we do not have indications that their absorption is suboptimal in CF mice. Malabsorption of medium-chain triglycerides is almost completely corrected after pancreatic enzyme replacement therapy in human patients with CF (15). Therefore, medium-chain triglyceride malabsorption is not likely to contribute to fat malabsorption in the pancreatic-sufficient CF mice in our study. A decrease in energy requirement is the most likely explanation for the improved body weight. To what extent the previous reported effects of $\mathrm{AB}$ on the intestine decreased the energy demand, and whether these changes are inversely related to body weight, remain to be evaluated. In veterinary medicine, several $A B$ are used as growth promoters, and these are probably mediated through suppression of Gram-positive intestinal bacteria (16). Of interest, our multiple-regression analysis revealed that the effect of $A B$ treatment on bacterial growth was gender-related, whereas none of the other parameters (e.g., bacterial classes in the small intestine (data not shown), fat absorption) were 
a

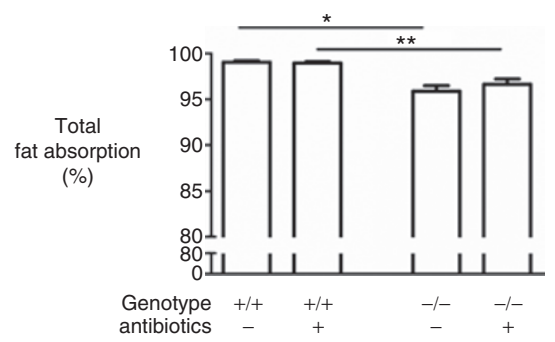

b

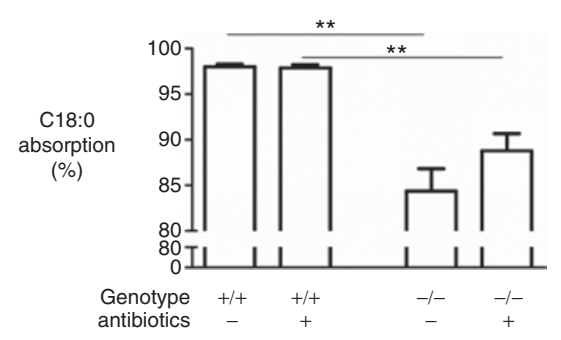

C

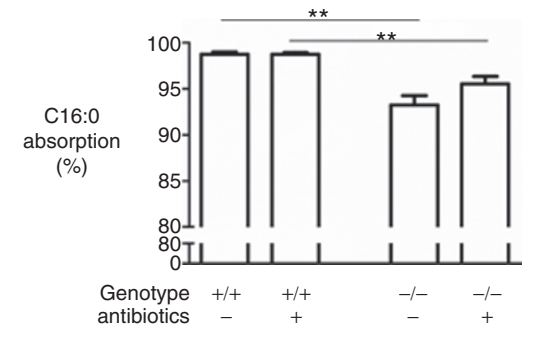

Figure 1. Fat absorption. (a) Total fat absorption and (b-c) absorption of the two major saturated fatty acids in cystic fibrosis transmembrane conductance regulator (CFTR) knockout mice (-/-) and their wild-type (WT) littermates (+/+) after antibiotic (AB) or control treatment. C16:0: palmitic acid. C18:0: stearic acid. Values are depicted as mean $\pm \mathrm{SEM}{ }^{*} P$ value $<0.05 .{ }^{*} P$ value $<0.01$.

a
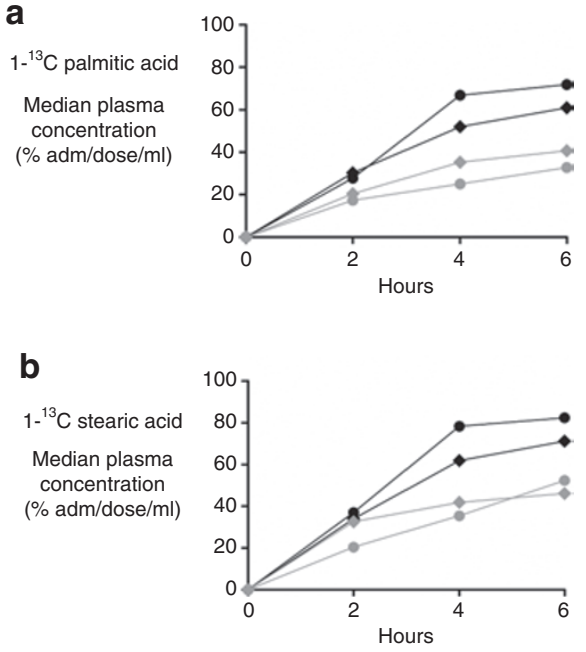

Figure 2. Fatty acid kinetics. ${ }^{13} \mathrm{C}$-enrichment in plasma after an intragastric bolus of stable isotope-labeled (a) tri-1 $1{ }^{13} \mathrm{C}$-palmitin and (b) $1{ }^{13} \mathrm{C}-$ stearate in antibiotic (AB)-treated homozygous $\Delta \mathrm{F} 508$ mice (black filled circles) and their wild-type (WT) littermates (black filled diamonds), and in control-treated homozygous $\Delta \mathrm{F} 508$ mice (gray filled circles) and their WT littermates (gray filled diamonds). Values are depicted as medians.

gender-related. There is no mechanism-based explanation for the observed effect.

$\mathrm{AB}$ accelerated LCFA uptake in homozygous $\triangle \mathrm{F} 508$ mice as well as in WT mice. The anticipated coefficient of variation of $10 \%$ was higher than expected, which may explain why there was significantly accelerated uptake of LCFA in the AB-treated animals (WT plus $\Delta \mathrm{F} 508$ ), whereas the rate of increase of uptake was not significant in the $\Delta \mathrm{F} 508$ mice group alone. The mechanism through which $\mathrm{AB}$ increase the plasma levels of orally administered fat is unclear. Given that $\mathrm{AB}$ did not alter the gallbladder bile salt composition in WT mice, and also did not change the major subclasses of bacteria in the small intestine, these factors probably do not contribute to the changes in fat absorption kinetics. Also, the fact that accelerated fatty acid uptake was observed in both CF and WT mice suggests an aspecific treatment effect on intestinal physiology, for example, on intestinal transit time, mucus composition, or the unstirred water layer. It has been previously shown that $\mathrm{AB}$ prolong the transit time in the small intestine in WT mice (13). The authors of the study hypothesized that normal microflora might play
Table 4 Area under the curve $1-{ }^{13} \mathrm{C}$ palmitic acid

\begin{tabular}{|c|c|c|c|}
\hline & $A B \%$ & Control \% & \\
\hline$\Delta / \Delta$ & $167(91-242)$ & $82(47-129)$ & $P=0.36$ \\
\hline \multirow[t]{2}{*}{$+/+$} & $138(128-198)$ & $94(90-132)$ & $P=0.08$ \\
\hline & $P=0.96$ & $P=0.29$ & $P=0.03$ (AB vs. control) \\
\hline
\end{tabular}

Table 5 Area under the curve $1{ }^{13} \mathrm{C}$ stearic acid

\begin{tabular}{|c|c|c|c|}
\hline & $A B \%$ & Control \% & \\
\hline$\Delta / \Delta$ & $198(145-250)$ & $111(43-158)$ & $P=0.12$ \\
\hline \multirow[t]{2}{*}{$+/+$} & $172(134-200)$ & $122(105-198)$ & $P=0.29$ \\
\hline & $P=0.64$ & $P=0.63$ & $P=0.03$ (AB vs. control) \\
\hline
\end{tabular}

${ }^{13} \mathrm{C}$-enrichment in plasma after an intragastric dosage of stable isotope-labeled $1{ }^{13} \mathrm{C}$ stearate in homozygous $\Delta F 508$ mice $(\Delta / \Delta)$ and WT littermates (+/+) after AB or control treatment. Data are expressed as median (range).

$A B$, antibiotic-treated; WT, wild-type.

an important role in the regulation of intestinal transit time (13). Given that homozygous $\Delta$ F508 mice have the same intestinal flora as WT, it is possible that intestinal transit is prolonged in $\triangle \mathrm{F} 508$ mice also, thereby enhancing intestinal fatty acid uptake. In addition, AB-induced bile flow is described in relation to some $\mathrm{AB}$, and this should be considered as a possible underlying mechanism (17). The biological significance of the changes in fatty acid kinetics remains to be determined. One could speculate that a reduction in the rate of fatty acid absorption indicates a more rate-limiting milieu in the small intestinal lumen, and a more gradual appearance of the dietary fat into the circulation. Whereas for carbohydrates the rate of appearance into the circulation is clearly associated with metabolic effects ("slow and rapid carbohydrates"), the corresponding effects of fat absorption rates remain largely unexplored. In the homozygous $\Delta \mathrm{F} 508$ mice, the decreased rate of uptake is adequately compensated for by an increase in the absorption capacity of the small intestine, resulting in a normal overall fat absorption. This compensatory capacity may be insufficient in patients with CF, in whom other phenomena also contribute to fat malabsorption (e.g., impaired lipolysis because of pancreatic insufficiency) or where more overt fat malabsorption 
Table 6 Bacterial-specific primers

\begin{tabular}{lll}
\hline Group & Reference strain & Primers \\
\hline Bac 338 & Escherichia coli & UniF340-ACTCCTACGGGAGGCAGCAGT \\
Eubacteria & & UniR514-ATTACCGCGGCTGCTGGC \\
Bac303 & Bacteroides fragilis & BactF285-GGTTCTGAGAGGAGGTCCC \\
Bacteroides & DSM 2151 & UniversalR338-GCTGCCTCCCGTAGGAGT \\
Erec & Ruminococcus productus & UniversalF338-ACTCCTACGGGAGGCAGC \\
Eubacterium rectale/Clostridium coccoides & DSM 2950 & CcocR491-GCTTCTTAGTCAGGTACCGTCAT \\
Labnew & Lactobaccillus acidophilus & LABF362-AGCAGTAGGGAATCTTCCA \\
Lactobacillus/Enterococcus & NIZO B228 & LABR677-CACCGCTACACATGGAG \\
\hline
\end{tabular}

165 rDNA group-specific and kingdom-specific primers for quantitative PCR $(26,27)$.

a

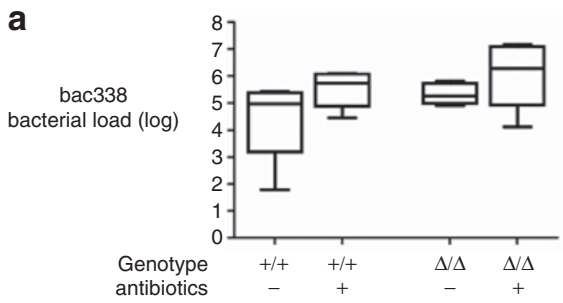

C

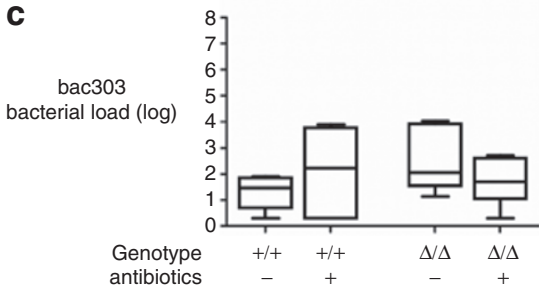

b
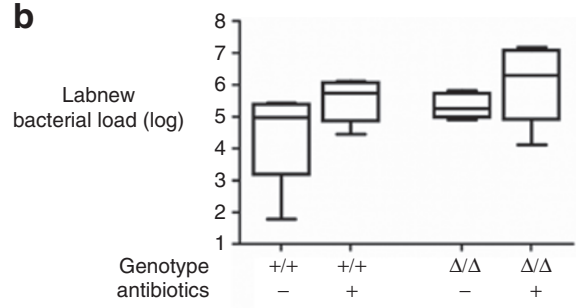

d

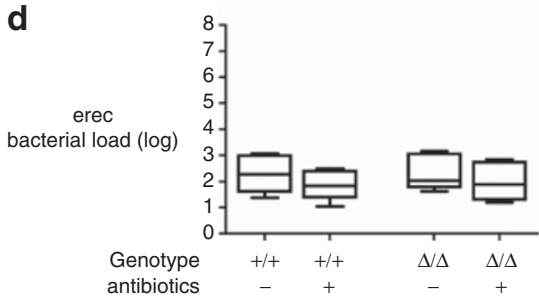

Figure 3. Bacterial load in small intestine. Number of copies of the bacterial load in the small intestine in homozygous $\Delta \mathrm{F} 508 \mathrm{mice}(\Delta / \Delta)$ and their wild-type (WT) littermates (+/+) after antibiotic (AB) or control treatment. Categories of bacterial groups: (a) Bac338, (b) Labnew, (c) Bac303, (d) Erec (Table 1). Box plot represents median and 25th and 50th centiles. Whiskers represent the lowest and highest values of the bacterial load.
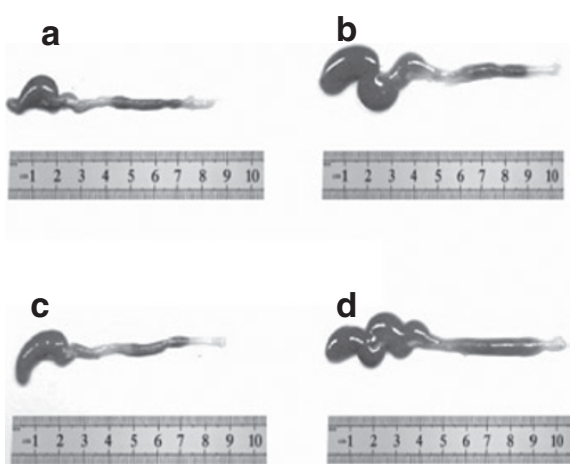

Figure 4. Colon. The colons of (a) antibiotic (AB)-treated homozygous $\triangle \mathrm{F} 508$ mice and (b) their wild-type (WT) littermates, and (c) controltreated homozygous $\Delta \mathrm{F} 508$ mice and (d) their WT littermates.

is present. This concept is especially interesting, because $\mathrm{AB}$ treatment has been shown to increase fat absorption by $\sim 20 \%$ in premature (non-CF) infants with overt fat malabsorption (18). Future studies in this area would lead to a better understanding of the exact role of $\mathrm{AB}$ in the absorption kinetics and/ or absorption of fat.

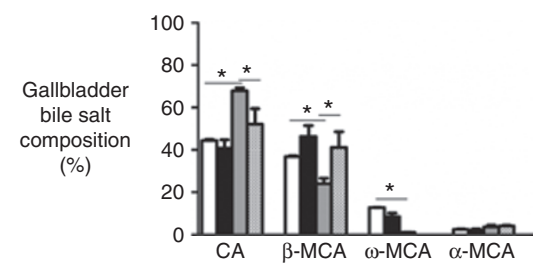

Figure 5. Biliary bile salt composition. Biliary bile salt composition in the gallbladders of antibiotic (AB)-treated homozygous $\Delta \mathrm{F} 508$ mice (hatched pattern) and their wild-type (WT) littermates (black), and in the gallbladders of control-treated homozygous $\Delta \mathrm{F} 508$ mice (gray) and their WT littermates (white). Bile salts representing $<2 \%$ of total bile salts are not depicted. CA, cholic acid; MCA, muricholic acid. ${ }^{*} P$ value $<0.05$.

$\mathrm{AB}$ treatment decreased fecal $\mathrm{CA}$ excretion in both $\mathrm{CF}$ mouse models. Our observation corresponds to the findings of an earlier report in patients with CF. In that study, a 7-day treatment with metronidazole reduced fecal bile salt excretion by $\sim 30 \%$ in three of four CF patients (11). Some studies have suggested that $\mathrm{AB}$ may have an inhibitory effect on bile salt synthesis in the liver $(19,20)$; this raises the possibility that the decrease in fecal CA is merely because of a reduced synthesis. Although we found a decrease in the percentage 
a
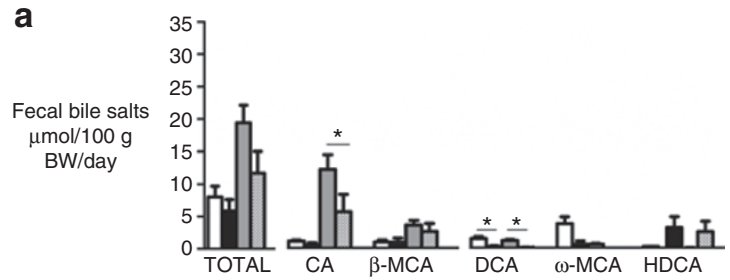

b

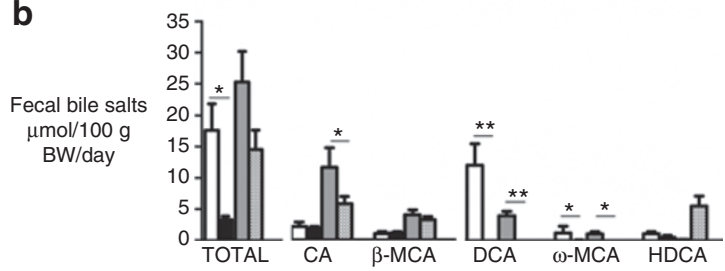

Figure 6. Fecal bile salt excretion. Fecal bile salt excretion in (a) homozygous $\Delta \mathrm{F} 508$ mice and (b) cystic fibrosis transmembrane conductance regulator (CFTR)-knockout mice and their respective wild-type (WT) littermates. Antibiotic (AB)-treated cystic fibrosis (CF) mice (hatched pattern) and their WT littermates (black); control-treated CF mice (gray) and their wild-type (WT) littermates (white). CA, cholic acid; DCA, deoxycholic acid; HDCA, hyoxydeoxycholic acid; MCA, muricholic acid. Values are depicted as mean $\pm \mathrm{SEM}{ }^{*} P$ value $<0.05,{ }^{* *} P$ value $<0.01$

contribution of $\mathrm{CA}$ in the bile of $\mathrm{AB}$-treated homozygous $\triangle$ F508 mice, this effect was not observed in WT animals. Therefore, we consider it more likely that the decrease in biliary CA is explained by a reduction in the synthesis of CA secondary to increased intestinal absorption. Fecal excretion of orally administered $24-\left[{ }^{14} \mathrm{C}\right] \mathrm{CA}$ decreased after $\mathrm{AB}$ treatment in human patients with $\mathrm{CF}(21)$. Our data therefore suggest an improved enterohepatic circulation of CA. Although we did not perform histology on the small intestine, we found a reduced mRNA expression of Muc2, a structural component of the intestinal mucus layer, in agreement with findings of previous studies in CFTR-knockout mice (12). We consider it unlikely that intestinal transit time could explain the observed changes in fecal bile salt excretion. The reduction in fecal excretion of CA in CFTR-knockout mice was similar to the reduction in the homozygous $\Delta \mathrm{F} 508$ mice, whereas (as previously indicated) $\mathrm{AB}$ did not change intestinal transit time in the CFTR-knockout mice (13). We found that the levels of the "classic" secondary bile salts such as deoxycholic acid and $\omega$-muricholic acid were reduced in the AB-treated animals. Of interest, however, the level of hyodeoxycholic acid (formed by $7 \beta$-hydroxylation) increased. Given that only certain strains of bacteria are capable of $7 \beta$-hydroxylation, it seems reasonable to assume that this shift in secondary bile salt formation is caused by AB-induced changes in bacterial colonization in the colon (8).

In conclusion, we showed that the growth-enhancing effect of $\mathrm{AB}$ treatment in CFTR-knockout mice is not attributable to increased fat absorption. $A B$ treatment accelerates fatty acid absorption in both homozygous $\triangle \mathrm{F} 508$ and WT mice and partially corrects the increased fecal excretion of bile salts in both $\mathrm{CF}$ mouse models. The potential therapeutic effect of $\mathrm{AB}$ on these parameters needs to be further explored, both in CF and in non-CF conditions.

\section{METHODS}

\section{Mice and Diet}

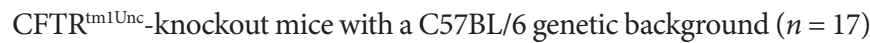
and WT littermates $(n=17)$ were reared in an environmentally controlled facility at the University of Kansas Medical Center. From the age of 10 days, the mice were maintained on a complete elemental liquid diet to prevent lethal intestinal obstruction (Peptamen; Nestlé, Deerfield, IL). The liquid diet contained $33 \%$ energy derived from fat (23\% of mediumchain triglycerides and $10 \%$ of long-chain triglycerides). The LCFAs in the diet were composed of: $16.4 \mathrm{~mol} \%$ palmitic acid, $6.7 \mathrm{~mol} \%$ stearic acid, $22.2 \mathrm{~mol} \%$ oleic acid, $43.6 \mathrm{~mol} \%$ linoleic acid, $4.6 \mathrm{~mol} \%$ a-linolenic acid, $0.1 \mathrm{~mol} \%$ arachidonic acid, and $0.06 \mathrm{~mol} \%$ docosahexaenoic acid. The experiment started when the animals were 3 weeks of age, and was performed as previously described (5). CFTR ${ }^{\text {tmlEur }}$ homozygous $\Delta \mathrm{F} 508$ mice with an FVB/129 genetic background $(n=8)$ and WT littermates $(n=8)$ were reared in an environmentally controlled facility at the Erasmus Medical Center (Rotterdam, the Netherlands). The mice had free access to water and a standard semisynthetic chow diet (Hope Farms, Woerden, the Netherlands). The diet contained 13\% energy derived from fat. The LCFA composition was similar to that in the liquid diet. The experiment was performed in mice between 8 and 11 weeks of age. Except for the CFTR-knockout mice in the control-treated group (male, $n=4$ ), both genders were equally represented in the groups after randomization. Except for body weight, no gender-related differences between parameters were observed.

The experimental protocols were approved by the University of Kansas Medical Center Institutional Animal Care and Use Committee and by the Ethical Committee for Animal Experiments of the Erasmus Medical Center in Rotterdam. The design was selected to allow comparison of the results with previously published data relating to the two genotypes $(5,7)$.

\section{Experimental Procedures}

$A B$ treatment. The $\mathrm{CF}$ mice and their respective WT littermates were individually housed. The experimental group received a 3-week (broad-spectrum) AB treatment (ciprofloxacin, $50 \mathrm{mg} / \mathrm{kg} /$ day and metronidazole, $100 \mathrm{mg} / \mathrm{kg} /$ day), as previously described (5). AB were administered to the liquid diet of the CFTR-knockout mice and their WT littermates. For the homozygous $\Delta$ F508 mice and their WT littermates, $\mathrm{AB}$ were administered in the drinking water, which was refreshed on a daily basis. Because of the light sensitivity of ciprofloxacin, the drinking bottles were covered with aluminium foil. Prior to the administration of $\mathrm{AB}$, the daily intakes of liquid diet and water per mouse were measured. Thereafter, the dose of $A B$ required per mouse was calculated and added to ensure an equal $A B$ dose, on average, for each of the mice. Addition of $A B$ did not affect the drinking behavior of the mice.

Fat balance study. After 3 weeks of AB treatment, a 72-h fat balance test was performed. During the last 3 days of treatment, the amount of dietary intake was noted and feces collected. Fecal pellets were freezedried and mechanically homogenized. Lipids were extracted from the samples, hydrolyzed, and methylated in accordance with the procedure described by Muskiet et al. (22). The resulting fatty acid methyl esters of LCFA were analyzed and quantified by gas chromatography, using heptadecanoic acid as an internal standard. The fat absorption coefficient (\%) was calculated by subtracting the fecal fat output (g/day) from the fat intake (g/day), divided by the fat intake (g/day) multiplied by $100 \%$.

Bile salt analysis. The total bile salt concentration was measured in an aliquot of feces (collected for the 3-day fat balance). In the homozygous $\Delta \mathrm{F} 508$ mice and their WT littermates, the bile salt concentration was measured in gallbladder bile. After deconjugation, bile salt profiles were determined by extracting the bile salts with commercially available Sep-Pak-C18 (Mallinckrodt Baker, Deventer, The 
Netherlands) cartridges and converting them to their methylester/ trimethylsilyl derivatives (23). Bile salt profiles were analyzed using capillary gas chromatography. The hydrophobicity of bile salts in gallbladder bile was calculated using the Heuman index, corresponding to the ability of bile salts to solubilize lipids (24).

Kinetics of fat absorption. The rate of intestinal uptake of triglycerides and fatty acids labeled with stable isotopes was determined in homozygous $\Delta$ F508 mice and their WT littermates. After 3 weeks of $\mathrm{AB}$ or control treatment (after finishing the 3-day fecal collection for estimation of fat balance), the mice were intraperitoneally injected with $1 \mathrm{mg} / \mathrm{kg}$ poloxamer of 407 to block lipoprotein lipasedependent lipolysis (25). Subsequently, a $100 \mu$ l bolus composed of olive oil (25\%) and medium-chain triglyceride oil (75\%) was intragastrically administered. This bolus contained $2 \mathrm{mg}{ }^{13} \mathrm{C}$-labeled tripalmitin and $2 \mathrm{mg}{ }^{13} \mathrm{C}$-labeled stearate per $30 \mathrm{~g}$ body weight. After bolus administration, the mice were deprived of food. Blood samples of $\sim 75 \mu \mathrm{l}$ were taken from the lateral tail vein before bolus administration and at 2, 4, and $6 \mathrm{~h}$ after bolus administration, using heparin-coated microhematocrit tubes. The mice were then killed by puncturing the heart. Plasma and erythrocytes were separated by centrifugation $\left(2,000\right.$ r.p.m., $10 \mathrm{~min}$ at $\left.4^{\circ} \mathrm{C}\right)$. The plasma samples were derivatized to their a-bromopentafluorobenzyl esters, and ${ }^{13} \mathrm{C}$-enrichment of $1-{ }^{13} \mathrm{C}$-palmitin and $1-{ }^{13} \mathrm{C}$-stearate was measured by gas chromatography combustion isotope ratio mass spectrometry (Delta S/GC Finnigan MAT, Bremen, Germany). ${ }^{13} \mathrm{C}$-enrichment in plasma was calculated from the fatty acid concentration and expressed as the percentage of the administered dose $/ \mathrm{ml}$ of plasma (\% dose $/ \mathrm{ml})$. Total plasma triglyceride concentrations were determined using commercially available kits (Roche Diagnostics, Mannheim, Germany).

Bacterial load in the small intestine. After the mice were killed, the small intestine was flushed with phosphate-buffered saline containing $10 \mathrm{mmol} / \mathrm{l} \mathrm{DTT}$ as a mucolytic agent. The eluent was centrifuged at 5,000 r.p.m. for $45 \mathrm{~min}$ to pellet the bacteria. Bacterial genomic DNA was isolated using the Qiagen DNA stool kit (Qiagen, Venlo, The Netherlands). Quantitative-PCR with an SYBR Green detection system (Bio-Rad MyIQ; Qiagen) was performed, using both group-specific and kingdom-specific primers $(26,27)$. Kingdom-specific primers for $16 \mathrm{~S}$ rDNA were used for the amplification of the total bacterial load, whereas group-specific primers were used for the quantification of each bacterial group. Each primer set was evaluated against reference bacterial strains for primer efficiency and specificity (Table 6).

$m R N A$ expression in the small intestine. Total RNA was isolated from the whole small intestine with TriReagent (Sigma, St Louis, $\mathrm{MO}$ ), washed with an RNA cleanup kit (RNeasy MinElute Cleanup kit; Qiagen) and quantified using a NanoDrop ND100 spectrophotometer (NanoDrop Technologies, Wilmington, DE). Relative mRNA expression for mucin 2 was determined using $5 \mu \mathrm{l}$ cDNA. Primers for mucin 2 were kindly provided by I. Renes, and PCR was carried out as previously described (28). PCR products were loaded on a $1 \%$ agarose gel and electrophoresed in a $1 \times$ tris-acetate-EDTA (TAE) buffer in the presence of ethidium bromide. Glyceraldehyde 3-phosphate dehydrogenase (GAPDH) was used as an internal control.

Statistical analysis. Statistical analysis was performed using SPSS 16.0 (SPSS, Chicago, IL). We calculated, with an anticipated coefficient of variation of $10 \%$, a required sample size of four per group to demonstrate a $30 \%$ decrease in fat malabsorption as compared to WT animals. Differences between experimental and control groups were calculated using the Mann-Whitney test. Data are reported as mean values \pm SD (SEM in figures) or as median (range) where the data were not normally distributed. $P$ values $<0.05$ were considered statistically significant. To exclude possible gender-related differences in treatment effect, we performed an additional multiple-regression analysis. Parameters for fat absorption, fecal bile salt excretion, and weight were included as dependent variables, whereas genotype, treatment, gender, and the interaction variable gender $\times$ treatment were included as independent variables.

\section{ACKNOWLEDGMENTS}

We thank H. Jorna, T. Boer, I. Martini, R. Boverhof, and S.C. Beijer-Liefers for their technical assistance.

\section{STATEMENT OF FINANCIAL SUPPORT}

This work was supported by National Institutes of Health grant R21 A1083479 and a pilot project as part of $\mathrm{NIH}$ grant P20 RR024214 (to R.C.D.).

\section{REFERENCES}

1. Sinaasappel M, Stern M, Littlewood J, et al. Nutrition in patients with cystic fibrosis: a European Consensus. J Cyst Fibros 2002;1:51-75.

2. Borowitz D, Durie PR, Clarke LL, et al. Gastrointestinal outcomes and confounders in cystic fibrosis. J Pediatr Gastroenterol Nutr 2005;41: $273-85$.

3. Saiman L, Anstead M, Mayer-Hamblett N, et al.; AZ0004 Azithromycin Study Group. Effect of azithromycin on pulmonary function in patients with cystic fibrosis uninfected with Pseudomonas aeruginosa: a randomized controlled trial. JAMA 2010;303:1707-15.

4. Saiman L, Marshall BC, Mayer-Hamblett N, et al.; Macrolide Study Group. Azithromycin in patients with cystic fibrosis chronically infected with Pseudomonas aeruginosa: a randomized controlled trial. JAMA 2003;290:1749-56.

5. Norkina O, Burnett TG, De Lisle RC. Bacterial overgrowth in the cystic fibrosis transmembrane conductance regulator null mouse small intestine. Infect Immun 2004;72:6040-9.

6. Rana SV, Bhardwaj SB. Small intestinal bacterial overgrowth. Scand J Gastroenterol 2008;43:1030-7.

7. Bijvelds MJ, Bronsveld I, Havinga R, Sinaasappel M, de Jonge HR, Verkade HJ. Fat absorption in cystic fibrosis mice is impeded by defective lipolysis and post-lipolytic events. Am J Physiol Gastrointest Liver Physiol 2005;288:G646-53.

8. Martin FP, Dumas ME, Wang Y, et al. A top-down systems biology view of microbiome-mammalian metabolic interactions in a mouse model. Mol Syst Biol 2007;3:112.

9. Savage DC, Dubos R. Alterations in the mouse cecum and its flora produced by antibacterial drugs. J Exp Med 1968;128:97-110.

10. Strandvik B, Einarsson K, Lindblad A, Angelin B. Bile acid kinetics and biliary lipid composition in cystic fibrosis. J Hepatol 1996;25:43-8.

11. O'Brien S, Mulcahy H, Fenlon $\mathrm{H}$, et al. Intestinal bile acid malabsorption in cystic fibrosis. Gut 1993;34:1137-41.

12. De Lisle RC, Roach EA, Norkina O. Eradication of small intestinal bacterial overgrowth in the cystic fibrosis mouse reduces mucus accumulation. J Pediatr Gastroenterol Nutr 2006;42:46-52.

13. De Lisle RC. Altered transit and bacterial overgrowth in the cystic fibrosis mouse small intestine. Am J Physiol Gastrointest Liver Physiol 2007;293:G104-11.

14. Norkina O, Kaur S, Ziemer D, De Lisle RC. Inflammation of the cystic fibrosis mouse small intestine. Am J Physiol Gastrointest Liver Physiol 2004;286:G1032-41.

15. Durie PR, Newth CJ, Forstner GG, Gall DG. Malabsorption of mediumchain triglycerides in infants with cystic fibrosis: correction with pancreatic enzyme supplement. J Pediatr 1980;96:862-4.

16. de Somer P, Eyssen H, Evrard E. The influence of antibiotics on fecal fat in chicks. In: Frazer AC, ed. Biochemical Problems of Lipids. Amsterdam: Elsevier, 1963:84-90.

17. Gonzalez J, Fernandez C, Marino E, Morales A, Jimenez R. Biliary excretion and choleretic effect of cefmetazole in rats. Antimicrob Agents Chemother 1989;33:1970-4.

18. Verkade HJ, van Asselt WA, Vonk RJ, et al. Fat absorption in premature infants: the effect of lard and antibiotics. Eur J Pediatr 1989;149:126-9. 
19. Le Dafniet M, Pessayre D, Le Quernec L, Erlinger S. Effects of troleandomycin administration on cholesterol 7 alpha-hydroxylase activity and bile secretion in rats. J Pharmacol Exp Ther 1981;219:558-62.

20. Toda T, Ohi K, Kudo T, et al. Ciprofloxacin suppresses Cyp3a in mouse liver by reducing lithocholic acid-producing intestinal flora. Drug Metab Pharmacokinet 2009;24:201-8.

21. Eklund A, Norman A, Strandvik B. Excretion of bile acids in healthy children and children with cystic fibrosis. Scand J Clin Lab Invest 1980;40:595-608.

22. Muskiet FA, van Doormaal JJ, Martini IA, Wolthers BG, van der Slik W. Capillary gas chromatographic profiling of total long-chain fatty acids and cholesterol in biological materials. J Chromatogr 1983;278:231-44.

23. Setchell KD, Worthington J. A rapid method for the quantitative extraction of bile acids and their conjugates from serum using commercially available reverse-phase octadecylsilane bonded silica cartridges. Clin Chim Acta $1982 ; 125: 135-44$.
24. Heuman DM. Quantitative estimation of the hydrophilic-hydrophobic balance of mixed bile salt solutions. J Lipid Res 1989;30:719-30.

25. Millar JS, Cromley DA, McCoy MG, Rader DJ, Billheimer JT. Determining hepatic triglyceride production in mice: comparison of poloxamer 407 with Triton WR-1339. J Lipid Res 2005;46:2023-8.

26. Barman M, Unold D, Shifley K, et al. Enteric salmonellosis disrupts the microbial ecology of the murine gastrointestinal tract. Infect Immun 2008;76:907-15

27. Salzman NH, de Jong H, Paterson Y, Harmsen HJ, Welling GW, Bos NA. Analysis of $16 \mathrm{~S}$ libraries of mouse gastrointestinal microflora reveals a large new group of mouse intestinal bacteria. Microbiology 2002;148(Pt 11): 3651-60.

28. van der Sluis M, Melis MH, Jonckheere N, et al. The murine Muc2 mucin gene is transcriptionally regulated by the zinc-finger GATA-4 transcription factor in intestinal cells. Biochem Biophys Res Commun 2004;325:952-60. 